DOI: 10.1002/ ((please add manuscript number))

Article type: Full paper

\title{
Toward robust segmented nanowires: Understanding the impact of crystallographic texture on the quality of segment interfaces in magnetic metallic nanowires
}

Jin Zhang, Salvador Pané, Jordi Sort*, Eva Pellicer*

J. Zhang, Dr. E. Pellicer

Departament de Física, Universitat Autònoma de Barcelona, E-08193 Bellaterra, Barcelona, Catalonia, Spain

Dr. Salvador Pané

Multi-Scale Robotics Lab (MSRL), Institute of Robotics \& Intelligent Systems (IRIS), ETH Zürich, Zürich 8092, Switzerland

Prof. J. Sort

Departament de Física, Universitat Autònoma de Barcelona, E-08193 Bellaterra, Barcelona, Catalonia, Spain

Institició Catalana de Recerca i Estudis Avaçats (ICREA), Barcelona, Catalonia, Spain

E-mail: Eva.Pellicer@uab.cat; Jordi.Sort@uab.cat

Keywords: segmented nanowires, interfaces, template-assisted electrodeposition, stair-case hysteresis loop, electrocrystallization

Segmented nanowires (NWs) have found a wealth of applications due to their multifuctionality, arising from complementarities and synergies among segments of different materials. However, to ensure a practical use of segmented NWs, high quality interfaces between dissimilar segments must be ensured. Herein, tri-segmented $\mathrm{CoPt} / \mathrm{Cu} / \mathrm{Ni} \mathrm{NWs}$ and bisegmented $\mathrm{CoPt} / \mathrm{Ni}$ magnetic NWs are fabricated by means of template-assisted electrodeposition and the characteristics of their interfaces are investigated in detail. The presence of a $\mathrm{Cu}$ segment sandwiched between the CoPt and the Ni segments severely affects the integrity of the whole NW. Namely, Cu deposits in a (200) textured face-centered cubic (fcc) structure, which cannot accommodate well on the $c$-axis oriented hexagonal closepacked CoPt. Instead, when the $\mathrm{Cu}$ segment is absent, well-connected $\mathrm{CoPt} / \mathrm{Ni} \mathrm{NWs}$ with smooth interface are obtained. Unlike the $\mathrm{Cu}$ segment, Ni shows the (111) textured fcc 


\section{WILEY-VCH}

structure, which holds good crystallographic matching with the underlying CoPt segment. Magnetic measurements reveal that $\mathrm{CoPt} / \mathrm{Ni} \mathrm{NWs}$ exhibit staircase-like hysteresis loops similar to the tri-segmented $\mathrm{CoPt} / \mathrm{Cu} / \mathrm{Ni} \mathrm{NWs}$. Such loop shape stems from the dissimilar coercivity between the hard $(\mathrm{CoPt})$ and soft $(\mathrm{Ni})$ segments. The bi-segmented NWs (with robust interfaces) are appealing for multi-bit recording media, magnetic nanoelectromechanical systems and magnetically-driven wireless drug delivery nanoplatforms. 


\section{WILEY-VCH}

\section{Introduction}

Owing to their unique chemical, size, shape and composition dependent properties, nanowires (NWs) have become appealing for a wide range of technological applications, including nanoelectronics, ${ }^{[1,2]}$ optoelectronics, ${ }^{[3,4]}$ catalysis ${ }^{[5]}$ sensing ${ }^{[6]}$ plasmonics, ${ }^{[7]}$ and drug delivery. ${ }^{[8,9]}$ Segmented NWs can be considered as an upgrade to single-component / singlephase NWs, as the combination of dissimilar materials within a nanoarchitecture leads to unique combined properties and synergies. Specifically, segmented NWs with magnetic properties have found several uses in devices such as giant magnetoresistance sensors, ${ }^{[10-12]}$ or biomedical transducers, ${ }^{[13]}$ among others. The ability to control the relative orientation of the magnetization between various magnetic segments in multi-component NWs can trigger new applications of these materials in multi-bit magnetic recording media ${ }^{[14,15]}$ or as synthetic ferrimagnets with reduced dipolar interactions for spin-valve sensors. ${ }^{[15,16]}$

A major challenge in assembling building blocks, such as segments of different materials consists of securing a good quality interface at the junctions, not only for ensuring the mechanical robustness of the final ensemble, but also for enabling an effective synergy or combination of properties. ${ }^{[17-20]}$ The occurrence of porous, wavy or cracked interfaces can severely affect or hinder the practical application of segmented NWs.

Electrodeposition inside the pores of anodized aluminum oxide (AAO) or polycarbonate (PC) membranes is frequently utilized to synthesize ordered arrays of segmented or layered magnetic NWs. ${ }^{[21-24]}$ To date, segmentation is achieved mainly by two different means: $(i)$ sequential electrodeposition by switching the working electrode between different electrolytes $^{[25,26]}$ or (ii) electrodeposition from a single bath by swapping the deposition potential or current density. ${ }^{[13,26-28]}$ The former approach minimizes the co-deposition of 


\section{WILEY-VCH}

different metals within the same segment and thus compositionally pure segments can be obtained.

In a previous work, the synthesis of tri-segmented $\mathrm{CoPt} / \mathrm{Cu} / \mathrm{Ni} \mathrm{NWs}$ by template-assisted electrodeposition was demonstrated. ${ }^{[26]}$ The possibility to tune the length of different segments in order to achieve room-temperature staircase-like hysteresis loops was proven. Full antiparallel alignment between hard ( $\mathrm{CoPt})$ and soft $(\mathrm{Ni})$ segments and, hence, zero remanent net magnetization rendered NWs with very weak dipolar interactions, thus minimizing their agglomeration in eventual biological applications. However, the characteristics of the different interfaces were not explored in detail. This is a serious issue in applications for which the NWs need to be released from the template because if the junctions are not well-built, then NWs unavoidable break up across the interface.

Herein, we present a detailed characterization of the interfaces in segmented hardferromagnetic/soft-ferromagnetic $\mathrm{CoPt} / \mathrm{Ni} \mathrm{NWs}$ with and without the presence of a nonmagnetic $\mathrm{Cu}$ spacer, obtained by sequential electrodeposition in PC membranes. Trisegmented $\mathrm{CoPt} / \mathrm{Cu} / \mathrm{Ni}$ and bi-segmented $\mathrm{CoPt} / \mathrm{Ni} \mathrm{NWs}$ are taken as model systems for studying the characteristics of the $\mathrm{CoPt} / \mathrm{Cu}, \mathrm{Cu} / \mathrm{Ni}$, and $\mathrm{CoPt} / \mathrm{Ni}$ interfaces. Contrary to the $\mathrm{CoPt} / \mathrm{Cu}$ interface, smooth and robust junctions are formed between $\mathrm{CoPt}$ and $\mathrm{Ni}$, thus ensuring a good adhesion between these two segments. The observed trends are rationalized on the basis of the different crystallographic features exhibited by $\mathrm{CoPt}, \mathrm{Cu}$, and $\mathrm{Ni}$ segments. Furthermore, magnetic measurements reveal that staircase-like hysteresis loops are obtained at room-temperature for both systems, even when $\mathrm{Cu}$ is absent between the two ferromagnetic segments. Our study highlights the importance of the interface quality in layered nanostructures in order to optimize their performance and guarantee a correct and reliable operation. 


\section{WILEY-VCH}

\section{Result and discussion}

The NWs were deposited inside the channels of a PC membrane (Figure 1). The PC backside was sputter-coated with a Au-Pd layer to make it conductive. CoPt was first electrodeposited followed by $\mathrm{Ni}(\mathrm{CoPt} / \mathrm{Ni} \mathrm{NWs})$ or followed by $\mathrm{Cu}$ and later $\mathrm{Ni}(\mathrm{CoPt} / \mathrm{Cu} / \mathrm{Ni} \mathrm{NWs})$. Details of different bath formulations and deposition parameters can be found elsewhere. ${ }^{[26]}$ The PC membrane was selected over AAO because the former is particularly well suited for further assessing the magnetic behavior of individual NWs still embedded in the template, as the pores are separated enough from each other (see Figure S1). Assessing the magnetic behaviour of isolated NWs, rather than the collective behaviour of the array is important in devices such as nanoelectronic machinery or magnetically driven drug delivery nanocarriers. Such information is obtained provided that the NWs are sufficiently separated from each other, so that interwire dipolar interactions are minimized. Besides, PC can withstand the alkaline electrolyte needed to electrodeposit hard-magnetic CoPt. According to several works on $\mathrm{CoPt}$ electrodeposition, hard-magnetic properties are easierly achieved in the as-deposited state when the alloy is plated from alkaline baths above room temperature, typically at $50-60{ }^{\circ} \mathrm{C} .{ }^{[29-}$

${ }^{31]}$ Under these conditions, Co-rich alloys with hexagonal close-packed phase are frequently obtained. Unfortunately, AAO cannot tolerate $\mathrm{pH}$ values beyond 8.2 (at room temperature) and undergoes dissolution in the electroplating bath, ${ }^{[32]}$ which is even exacerbated at higher temperatures. The NWs had a mean diameter of $100 \mathrm{~nm}$ and the overall length was ca. $3.6 \mu \mathrm{m}$ for the bi-segmented and $5 \mu \mathrm{m}$ for the tri-segmented NWs. For the CoPt segment, deposition conditions were optimized so that a Co-rich alloy with $\mathrm{Co}_{70} \mathrm{Pt}_{30}$ stoichiometry was obtained. $^{[26]}$ 


\section{WILEY-VCH}

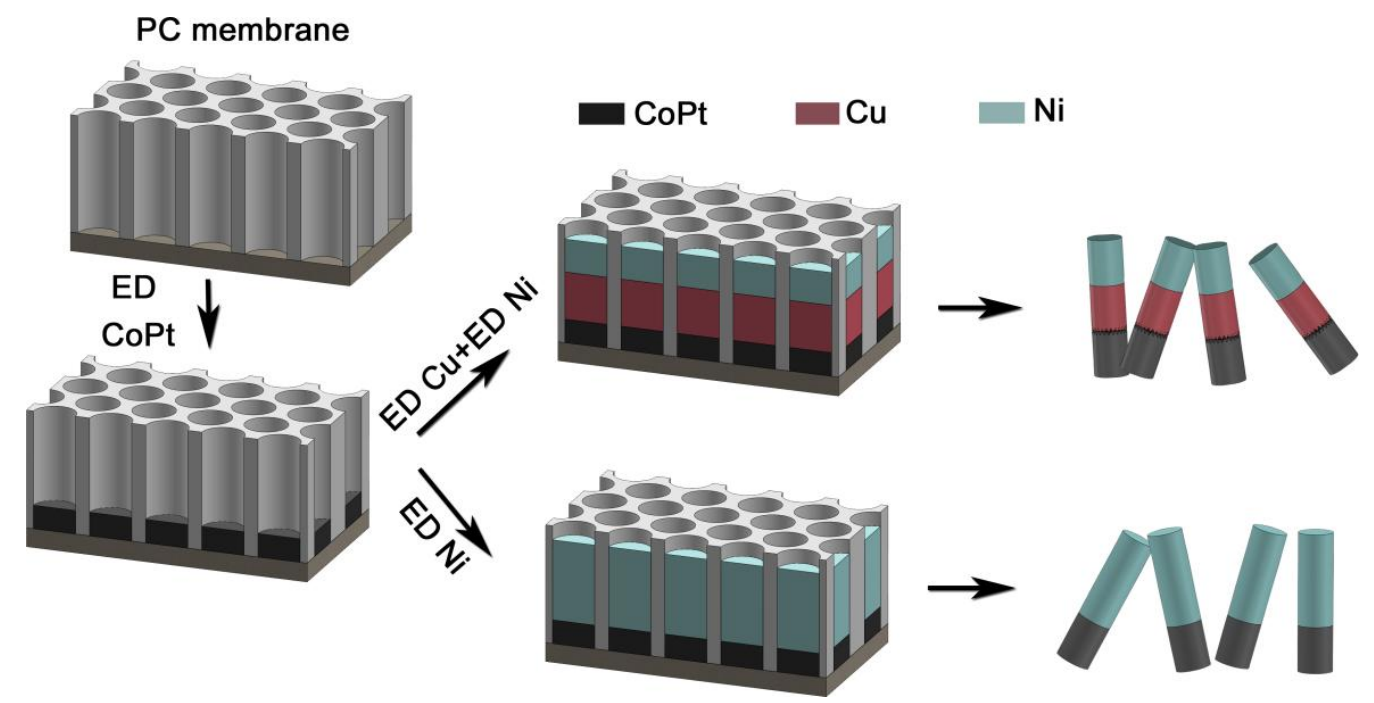

Figure 1. Scheme of the fabrication process of tri-segmented $\mathrm{CoPt} / \mathrm{Cu} / \mathrm{Ni}$ and bi-segmented $\mathrm{CoPt} / \mathrm{Ni} \mathrm{NWs}$.

A backscattered electrons SEM image of the tri-segmented $\mathrm{CoPt} / \mathrm{Cu} / \mathrm{Ni} \mathrm{NWs}$ is shown in Figure 2a, in which $\mathrm{CoPt}$ and $\mathrm{Cu}$ segments can be easily distinguished thanks to their different contrast (CoPt looks bright while $\mathrm{Cu}$ looks dark). The $\mathrm{CoPt} / \mathrm{Cu}$ junctions look rather discontinuous and some NWs have broken along the $\mathrm{CoPt} / \mathrm{Cu}$ interface. On the contrary, it is difficult to locate the boundary between the $\mathrm{Cu}$ and the $\mathrm{Ni}$ segments because both elements possess similar atomic weights (i.e., they have similar electron dispersing capability and, hence, contrast under SEM). Moreover, no defects such as cracks or pores, that could eventually reveal the location of the interface, were detected. Therefore, the interface between $\mathrm{Cu}$ and $\mathrm{Ni}$ is seemingly very smooth. A zoomed view of $\mathrm{CoPt} / \mathrm{Cu}$ junction was further taken by TEM. Figure $1 \mathrm{~b}$ shows severely cracked and/or porous interfaces between the CoPt and the $\mathrm{Cu}$ segments. Notice that here the contrast is opposite to the SEM (CoPt looks darker than $\mathrm{Cu})$. The occurrence of such defective junctions unavoidably leads to the detachment of many CoPt segments when the NWs are released from the PC membrane. As a result, multiple broken NWs are observed by both SEM and TEM. 


\section{WILEY-VCH}
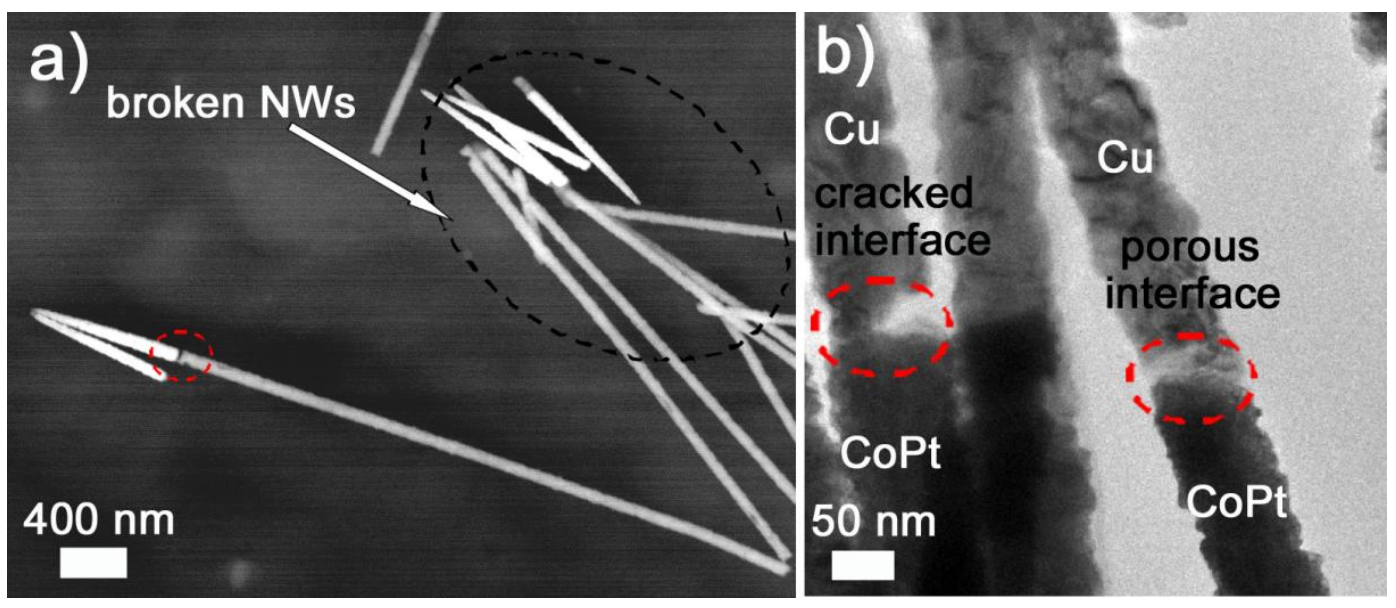

Figure 2. (a) Back-scattered electrons SEM image of tri-segmented $\mathrm{CoPt} / \mathrm{Cu} / \mathrm{Ni} \mathrm{NWs}$. The red dotted circle embraces the $\mathrm{CoPt} / \mathrm{Cu}$ interface. The big black dotted circle and the arrow points to a group of broken NWs (b) TEM image of the $\mathrm{CoPt} / \mathrm{Cu}$ interfaces in tri-segmented $\mathrm{CoPt} / \mathrm{Cu} / \mathrm{Ni} \mathrm{NWs}$.

Figure 3a shows a representative SEM image of a bi-segmented CoPt/Ni NW. Unlike the trisegmented case, detached CoPt segments are rarely observed by SEM. TEM imaging further reveals that the CoPt and the Ni segments are well attached (Figure 3b). The corresponding lengths can be straightforwardly determined thanks to the contrast. Under the applied electrodeposition conditions, ${ }^{[26]}$ the CoPt segment is $0.9 \mu \mathrm{m}$ long and the Ni segment has a length of $2.9 \mu \mathrm{m}$.
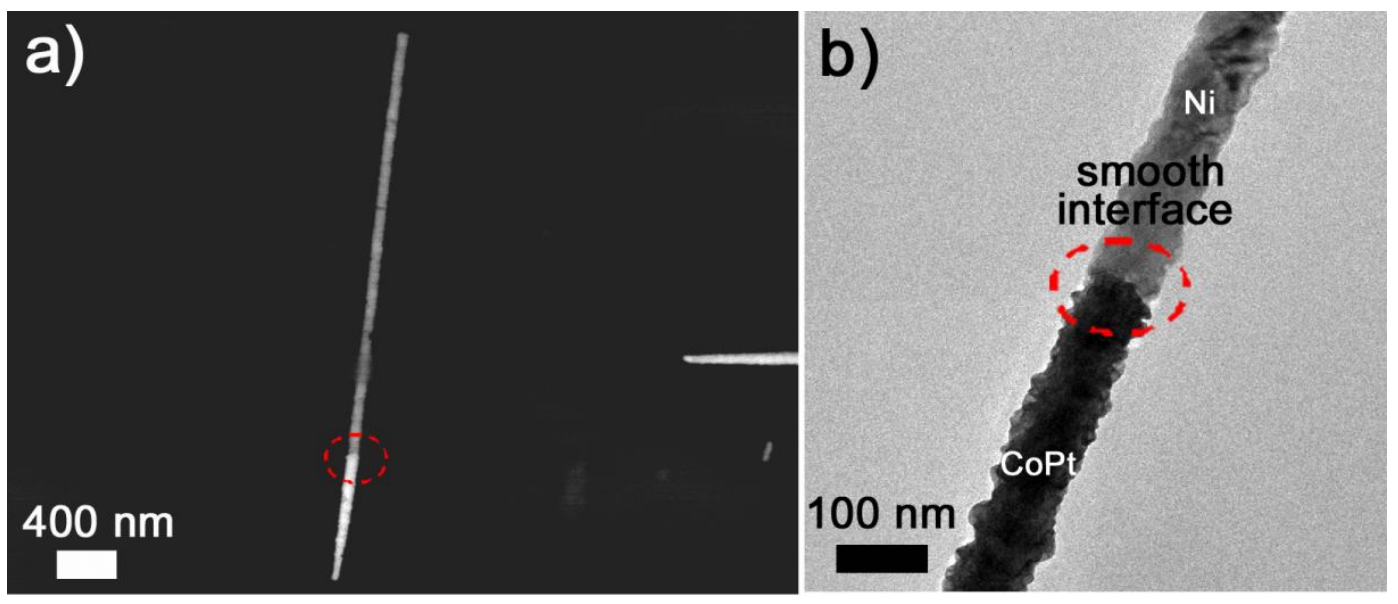

Figure 3. (a) Back-scattered electrons SEM and (b) TEM images of a bi-segmented CoPt $/ \mathrm{Ni}$ NW. The red dotted circles embrace the CoPt/Ni interface. 


\section{WILEY-VCH}

It is known that the structure and properties of a deposit are greatly influenced by the piling layer upon which plating is carried out. ${ }^{[33]}$ Besides, adhesion of deposits to the piling layer is greatly affected by texture. It is conjectured that the defective interface between the CoPt and the $\mathrm{Cu}$ segments is mainly due to lattice mismatch. To verify this hypothesis, NWs made of either $\mathrm{CoPt}, \mathrm{Ni}$ or $\mathrm{Cu}$ were electrodeposited inside the PC membrane using the same baths and deposition parameters as for the segmented cases. X-ray diffraction (XRD) analyses of the individual (non-segmented) $\mathrm{CoPt}, \mathrm{Ni}$ and $\mathrm{Cu}$ NWs embedded in the PC membrane were carried out and the results are presented in Figure 4. All the diffractograms show peaks arising from the Au-Pd conductive layer sputtered onto the PC backside before electrodeposition. In the case of $\mathrm{Cu}$ NWs, four diffraction peaks at $2 \theta=43.3^{\circ}, 50.4^{\circ}, 74.1^{\circ}$ and $89.9^{\circ}$, ascribed to the (111), (200), (220) and (311) reflections, respectively, of the facecentered cubic (fcc) phase, are observed. By comparing the tabulated and experimental peak intensities (I) of (111) and (200) reflections, some conclusions can be drawn. The ratio of the integral intensity of the (200) peak to that of the (111) peak, $I_{(200)} / I_{(111)}$, is 1.02, which is larger than the tabulated value for randomly oriented $\mathrm{Cu}(0.46) .{ }^{[34]}$ This indicates the growth of $\{100\}$ textured $\mathrm{Cu}$ during the electrodeposition process. Duan et al. ${ }^{[35]}$ have previously reported the occurrence of various textures in fcc-Cu films depending on the electrodeposition conditions (pH, applied potential and temperature). The $\{100\}$ or $\{110\}$ textures are obtained at relatively high $\mathrm{H}$ ions concentration in the bath, since $\mathrm{H}$ ions are prone to be adsorbed in the (100) and (110) high-surface-energy planes, causing a reduction of their surface energies to values even lower than for the $\{111\}$ planes, thus promoting crystallographic texture along these directions. Hence, in our case, the rather acidic $\mathrm{pH}$ (3.93) could favor the $\{100\}$ texture in $\mathrm{Cu}$, at the expense of the most densely packed $\{111\}$ planes. For Ni NWs, the fcc phase is also obtained. The experimental $I_{(200)} / I_{(111)}$ ratio is 0.04 , which in this case is much smaller than the theoretical ratio for randomly oriented $\mathrm{Ni}$ grains $(0.42) .{ }^{[34]}$ Hence, Ni shows the $\{111\}$ texture. Again, the occurrence of texture in electrodeposited Ni coatings depends on 


\section{WILEY-VCH}

the electrolyte composition and the operating conditions and typically there is not a sole origin. As observed by Amblard et al., ${ }^{[36]}$ the electrocrystallization of Ni is a highly inhibited process. Adsorbed hydrogen $\left(\mathrm{H}_{\mathrm{ads}}\right)$ species generated during electrodeposition are regarded as inhibitors for Ni deposition. In acid plating baths, the concentration of protons $\left(\mathrm{H}^{+}\right)$at the cathode neighborhood is large. They are discharged and immediately adsorbed onto the cathode, leading to its rapid depletion and a local increase of the $\mathrm{pH}$ at the Ni/electrolyte interface. This, in turn, promotes the precipitation of $\mathrm{Ni}(\mathrm{OH})_{2}$, which is believed to be another inhibiting species for metallic Ni deposition and to 'promote' a given mode of growth. Namely, (111)-oriented Ni deposits become stabilized by $\mathrm{Ni}(\mathrm{OH})_{2}$. The occurrence of texture can be also explained from the different growth rate of crystal facets. ${ }^{[37]}$ Using a purely geometric argument, it can be demonstrated that fast growing faces grow out of existence whereas slow growing crystal faces survive. Densest faces have the slowest growth velocity. For the fcc, the velocity follows the order: $\{111\}<\{110\}<\{100\}$ and, therefore, the (111) facet preferentially develops.

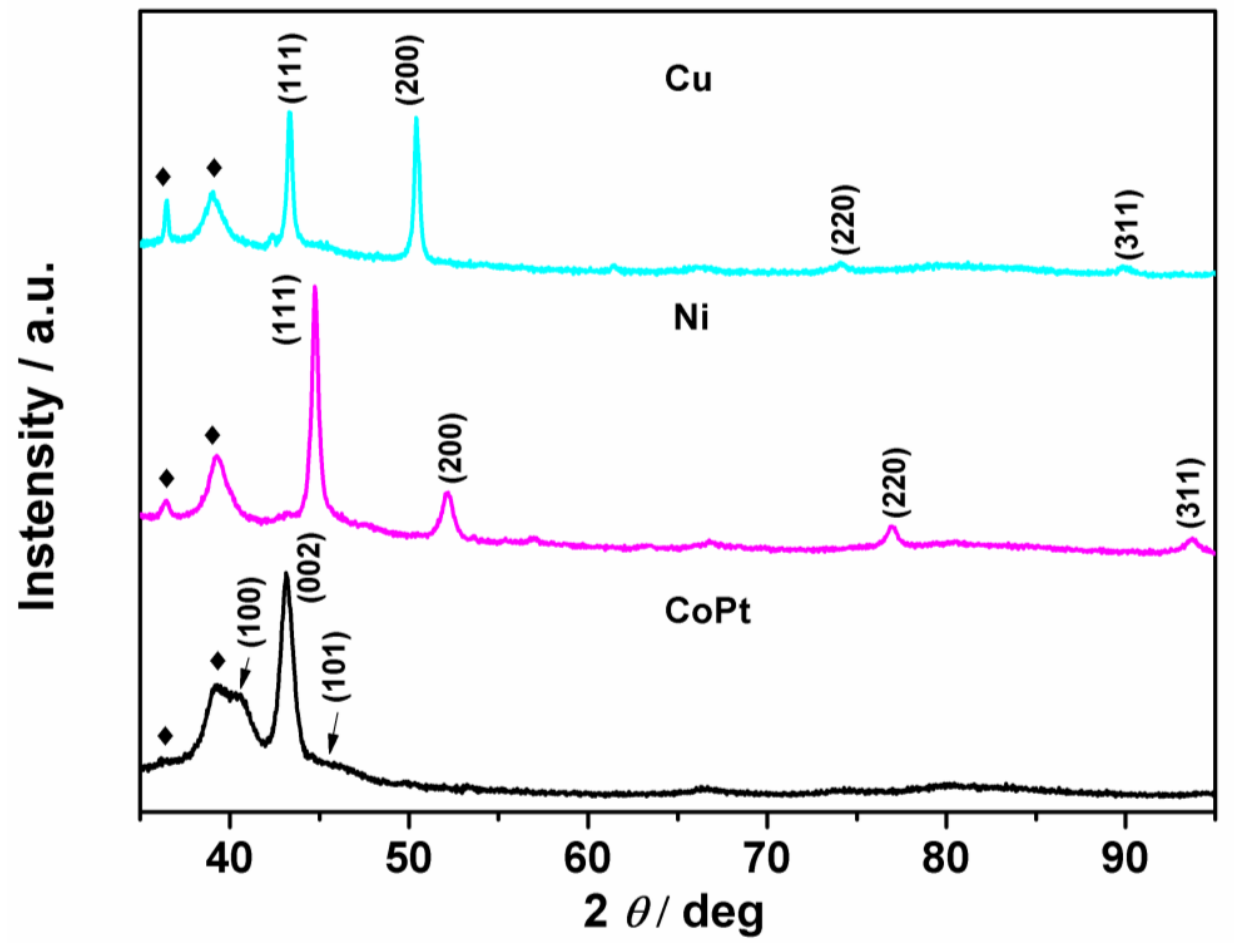

Figure 4. XRD patterns of non-segmented $\mathrm{Cu}, \mathrm{Ni}$ and $\mathrm{CoPt} \mathrm{NW}$ arrays. Peaks denoted by belong to the sputtered Au-Pd conductive layer onto the PC membrane. 


\section{WILEY-VCH}

The diffractogram for CoPt NWs is also shown in Figure 3. The most intense peak at $43.1^{\circ}$ matches the $2 \theta$ position expected for either (002) hexagonal-closed packed (hcp) or (111) fcc phase of Co. The absence of a diffraction peak at ca. $51.5^{\circ}$ (which should match the angular position of the (200) peak for fcc-Co), suggests that CoPt has fully crystallized in the hcp structure. ${ }^{[38]}$ Moreover, the intensity of the (101) reflection is dramatically reduced as compared to the standard powder pattern, which suggests that the hexagonal $c$ axis lies preferentially along the long axis of the NWs. ${ }^{[39,40]}$ This means that PtCo is also crystallographically textured, here in the [002] direction.

In order to verify whether the observed textures were maintained for the bi- and the trisegmented NWs, the XRD patterns of $\mathrm{CoPt} / \mathrm{Cu} / \mathrm{Ni}$ and $\mathrm{CoPt} / \mathrm{Ni} \mathrm{NW}$ arrays embedded in the PC membrane were recorded (Figure 5). On comparing the profiles with those of Figure 4, the peaks coming from $\mathrm{CoPt}, \mathrm{Cu}$ and $\mathrm{Ni}$ phases can be straightforwardly identified in the trisegmented $\mathrm{CoPt} / \mathrm{Cu} / \mathrm{Ni} \mathrm{NWs}$ diffractogram. Likewise, the peaks corresponding to $\mathrm{CoPt}$ and $\mathrm{Ni}$ phases show up in the bi-segmented CoPt/Ni NWs pattern. CoPt maintains the (002) preferred orientation, as for the non-segmented case. This is predictable since CoPt is firstly deposited (i.e., it deposits onto the AuPd layer both in the non-segmented and segmented cases). Regarding the Ni segments, the relatively high intensity of the Ni (111) peak over the (200) suggests the occurrence of texture (both in the bi- and tri-segmented cases), similar to the non-segmented case. However, the $I_{(200)-N i} / I_{(111)-N i}$ ratio cannot be precisely quantified due to partial overlapping of the $\mathrm{Ni}(111)$ with $\mathrm{CoPt}(002)$ peaks. Concerning the $\mathrm{Cu}$ signal in the $\mathrm{CoPt} / \mathrm{Cu} / \mathrm{Ni}$ diffractogram, although the (111) reflection is masked by the (002) peak from CoPt phase, the relatively large intensity of the $\mathrm{Cu}$ (200) reflection suggests the occurrence of $\{100\}$ texture as for the non-segmented $\mathrm{Cu}$ NWs. 


\section{WILEY-VCH}

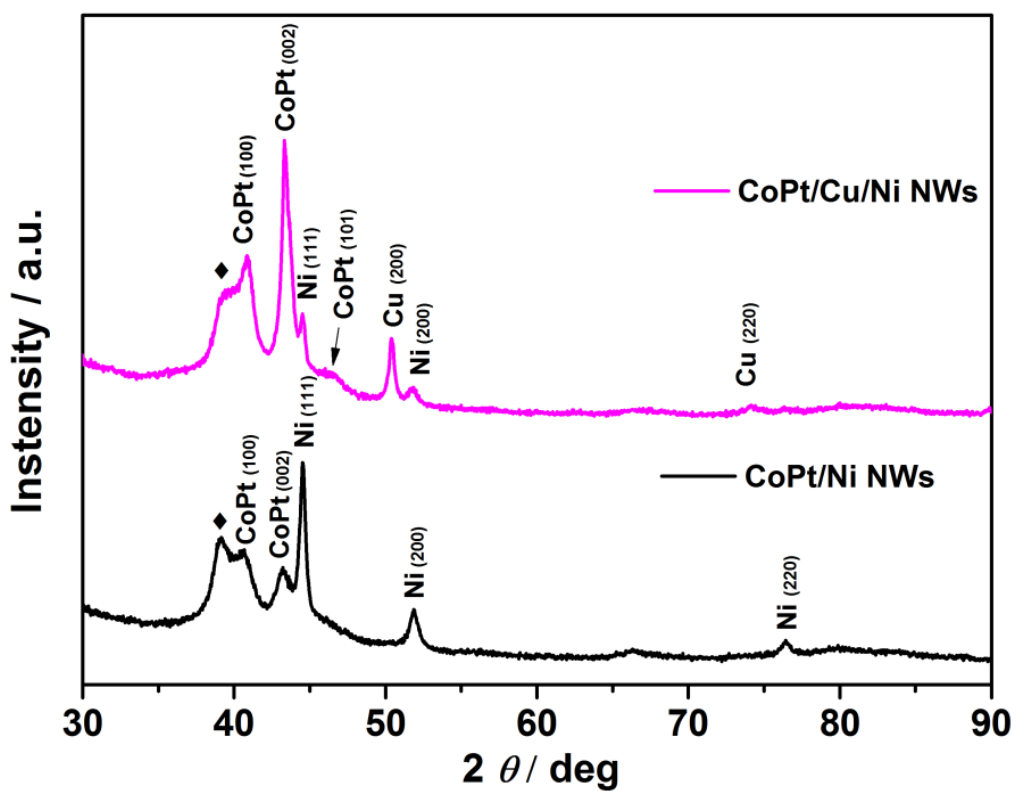

Figure 5. XRD patterns of tri-segmented $\mathrm{CoPt} / \mathrm{Cu} / \mathrm{Ni}$ and bi-segmented $\mathrm{CoPt} / \mathrm{Ni} \mathrm{NWs}$. Peaks denoted by belong to the sputtered $\mathrm{Au}-\mathrm{Pd}$ conductive layer.

Considering the aforementioned structural features, one can actually anticipate the rather poor adhesion between $\mathrm{CoPt}$ and $\mathrm{Cu}$ segments. Since they grow in different crystallographic phases (hcp versus fcc), cracked and porous interfaces develop due to severe lattice mismatch. Analogous results were previously observed between hcp-Co and fcc-Au in multi-segmented $\mathrm{Au} / \mathrm{Co} / \mathrm{Au}$ NWs. ${ }^{[41]}$ Meanwhile, even though $\mathrm{CoPt}$ and $\mathrm{Ni}$ also grow in different crystallographic structures, the adhesion between the segments is reasonably good. This can be understood taking the textures previously observed by XRD into account. The (001) planes of hcp-CoPt and the (111) planes of fcc-Ni are planes of highest atomic packing (i.e., densest possible arrangements of atoms in 2D). Both can be described as a compact hexagonal arrangement of atoms in 2D, being structurally analogous to each other ${ }^{[42]}$ Indeed, the densest packing fashion along the [111] orientation of fcc phase matches the [001] oriented hcp planes (Figure 6). It is known that duplication of the structure of the piling layer favors good connection and therefore a smooth interface between the CoPt segment and the subsequent $\mathrm{Ni}$ 


\section{WILEY-VCH}

segment builds up. Such structural equivalence does not hold between the (001) planes of hcp-CoPt and the (100) planes of fcc-Cu.

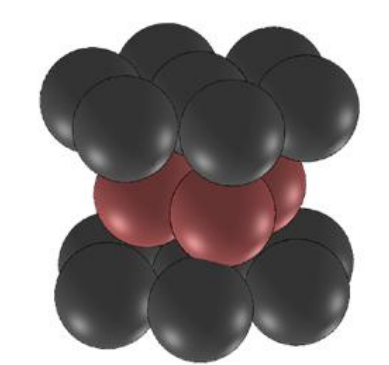

CoPt (001) hcp

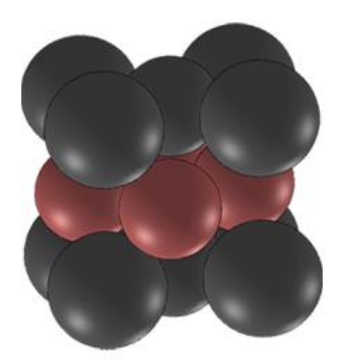

$\mathrm{Cu}(100) \mathrm{fcc}$

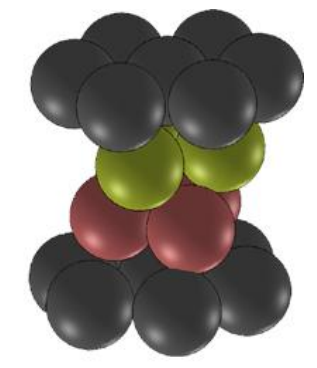

$\mathrm{Ni}(111)$ fcc
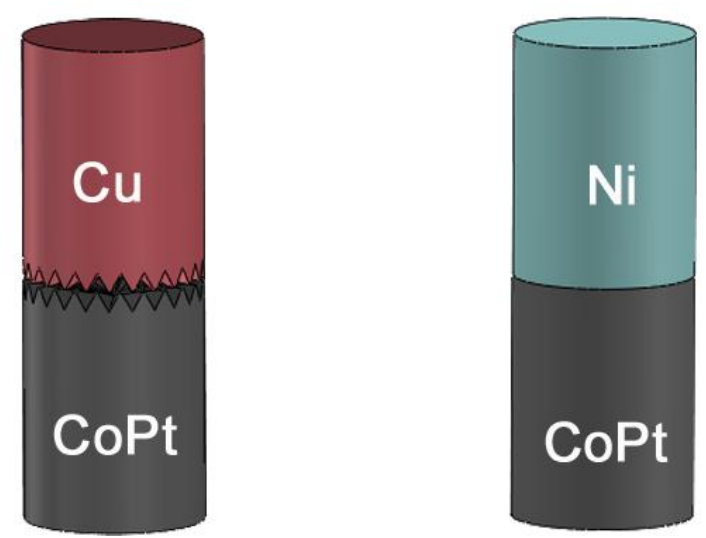

Figure 6. Putative densest packing of $\mathrm{CoPt}, \mathrm{Cu}$ and $\mathrm{Ni}$ and schematic drawing of the interface in $\mathrm{CoPt} / \mathrm{Cu}$ and $\mathrm{CoPt} / \mathrm{Ni}$.

The defective interface between $\mathrm{CoPt}$ and $\mathrm{Cu}$ segments was characterized in detail by TEM and EDX (see Figure S2). As mentioned above, the overt contrast reveals where the CoPt segment ends and where the $\mathrm{Cu}$ segment begins. The $\mathrm{Cu}$ segment is barely connected to the CoPt i.e., the formation of a severely cracked interface occurs, which will preclude the further assessment of the interface length. However, an EDX spectrum (see Figure S2b) recorded on the red dot "b" in Figure S2a from the cracked interface where the brighter segments begins exhibits that only $\mathrm{Cu}$ was detected. The changes in composition from $\mathrm{CoPt}$ to $\mathrm{Cu}$ are rather abrupt. And no codepostion occurred. 


\section{WILEY-VCH}

Despite $\mathrm{Cu}$ and $\mathrm{Ni}$ segments possess a different fcc texture, the $\mathrm{Cu} / \mathrm{Ni}$ junction is rather difficult to be distinguished by both SEM and TEM, as mentioned above. For this reason, STEM-EDX line scan analysis was performed on a scanning transmission electron microscope (STEM) in order to determine the composition profile at the interface. Figure S3a shows a TEM image featuring a whole tri-segmented NW at the center. The EDX line scan was done along the portion enclosed in the red box in Figure S3a, therefore capturing the $\mathrm{Cu} / \mathrm{Ni}$ interface composition. It can be seen that this portion embraces a porous region (right) and a denser region featuring brighter contrast (left) (Figure S3a). Porosity in $\mathrm{Cu}$ can be attributed to the hydrogen co-evolution that accompanies cations discharge at the potential applied for $\mathrm{Cu}$ segment growth $(E=-1 \mathrm{~V}$ vs. $\mathrm{Ag} / \mathrm{AgCl})$. As a result, deposits consisting of agglomerates of $\mathrm{Cu}$ grains are typically obtained. ${ }^{[43]}$ As shown in Figure $\mathrm{S} 3 \mathrm{~b}$, both $\mathrm{Cu}$ and $\mathrm{Ni}$ are detected within the analyzed portion. As the beam is scanning the NW toward the Ni segment, the Ni signal monotonically increases whereas the $\mathrm{Cu}$ signal starts to decrease. This proves that there is not an abrupt change in composition but rather $\mathrm{Cu}$ and $\mathrm{Ni}$ are present within a distance larger than $100 \mathrm{~nm}$, thus rendering a relatively thick interface. It is conjectured that a small electrolyte volume remains entrapped inside the pores of the PC membrane after $\mathrm{Cu}$ deposition. Upon switching to the $\mathrm{Ni}$ bath, the residual $\mathrm{Cu}^{2+}$ ions mix with the $\mathrm{Ni}$ electrolyte constituents. As a result, $\mathrm{Cu}-\mathrm{Ni}$ might get codeposited within the first stages of $\mathrm{Ni}$ segment deposition. Cu-deposition is indeed thermodynamically favored at the current density applied for Ni deposition $\left(-10 \mathrm{~mA} \mathrm{~cm}^{-2}\right) \cdot{ }^{[44]}$ Another possibility would be that $\mathrm{Ni}$ deposits in the upper voids left by the porous $\mathrm{Cu}$ segment until a flat $\mathrm{Ni}$ layer is formed. However, if this were the case one would expect greater fluctuation of the $\mathrm{Cu}$ and $\mathrm{Ni}$ signals along the EDX-line scan (i.e., $\mathrm{Cu}$ and $\mathrm{Ni}$ signals would somehow alternate).

To get a better insight into the morphology of the well-formed $\mathrm{CoPt} / \mathrm{Ni}$ interface, bisegmented CoPt/Ni NWs were further examined by HRTEM and STEM-EDX line analyses. As shown in Figure 7a, (111) textured Ni exhibits excellent adhesion to the (002) oriented 


\section{WILEY-VCH}

hcp CoPt segment. When the electron beam was spotted onto the bright region in Figure 7a, only $\mathrm{Ni}$ was detected. The $\mathrm{Ni}$ signal gradually decreases down to negligible levels as the electron beam is swept through the Ni/CoPt interface (Figures $7 \mathrm{~b}$ and 7c). Meanwhile, Co and Pt signals simultaneously increase until a constant value, leading to a $\mathrm{Co} / \mathrm{Pt}$ atomic ratio of 7:3. The change from pure Ni to pure CoPt is accomplished within $20 \mathrm{~nm}$. The resulting interface is thus thinner than for $\mathrm{Cu} / \mathrm{Ni}$. Figure 7c shows an HRTEM image of the junction, which proves the fine adhesion of $\mathrm{Ni}$ onto $\mathrm{CoPt}$. Although the $\mathrm{Ni}$ segment is in fact polycrystalline, as observed by HRTEM (Figure 7d), many of the lattice fringes perpendicular to the NWs long axis could be assigned to the interplanar distance of (111) fcc $(d=0.2033$ $\mathrm{nm})$. Therefore, the presence of a large population of (111) facets would favor a good connection to the CoPt segment.
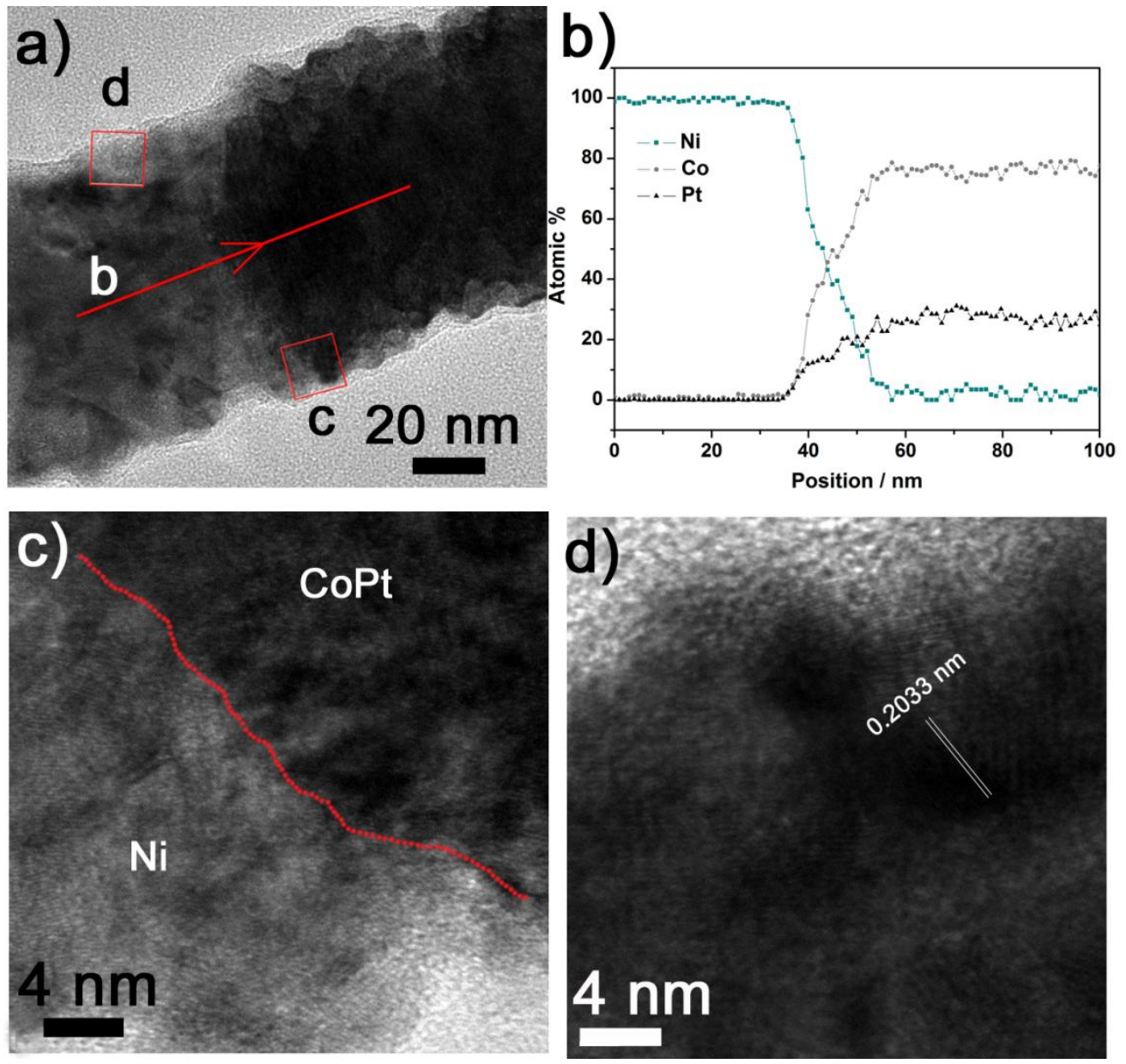


\section{WILEY-VCH}

Figure 7. a) TEM image of the interface between Ni (left) and CoPt (right) segments in bisegmented CoPt/Ni NWs. b) line-scan STEM-EDX analysis across the interface depicted with the red arrow in a), c) HRTEM image of the area enclosed with the red square labelled as ' $c$ ' in a), corresponding to the interface. d) HRTEM image of the area enclosed with the red square labelled as ' $d$ ' in a), corresponding to the Ni segment.

Hysteresis loops of segmented $\mathrm{CoPt} / \mathrm{Cu} / \mathrm{Ni}$ and $\mathrm{CoPt} / \mathrm{Ni} \mathrm{NWs}$ embedded inside the PC membrane were measured along the long axis of the NWs, as shown in Figure 8. The magnetic dipolar interactions between neighboring NWs in PC membranes can be neglected, owing to the relatively large interpore distance (much larger than the pore diameter, very often exceeding $200 \mathrm{~nm}$ ). Hence, in a first approximation, the loops correspond to the behavior of isolated, non-interacting NWs. Interestingly, both hysteresis loops reveal the magnetization switching of $\mathrm{CoPt}$ and $\mathrm{Ni}$, since the two segments have different values of coercivity. ${ }^{[26]}$ Although clear staircase-like hysteresis loops were expected for the trisegmented case, this was not necessarily the case for the bi-segmented NWs. In principle, magnetic exchange interactions between $\mathrm{CoPt}$ and $\mathrm{Ni}$ should take place in the absence of a non-magnetic spacer $(\mathrm{Cu})$ and, therefore, non-stepped loops might be obtained if the reversal of $\mathrm{Ni}$ and $\mathrm{CoPt}$ occurred simultaneously. However, magnetic measurements reveal that exchange interactions between $\mathrm{CoPt}$ and $\mathrm{Ni}$ in the bi-segmented NWs are not sufficient to force such simultaneous reversal, probably due to the small interface area between the two segments (as compared to their overall volume). Consequently, the two switching events can be separately observed, similar to what typically occurs in many types of exchange-interacting spring-magnets. ${ }^{[45,46]}$ Moreover, even if Ni spins close to the interface would be pinned to some extent by CoPt, the spins at the center of the soft segment would be free to follow the external field, given the much longer length of $\mathrm{Ni}$ segmentsas compared to CoPt ones.Once the applied magnetic field exceeds the exchange field, the spins in the Ni segment exhibit a continuous rotation, leading to a relatively steep magnetization reversal. ${ }^{[46]}$ The different ratios between the relative magnetization of the $\mathrm{Ni}$ and $\mathrm{CoPt}$ segments in tri- and bi- 


\section{WILEY-VCH}

segmented NWs are simply due to the dissimilar relative segment lengths in the two investigated systems, bearing in mind that the saturation magnetization of $\mathrm{CoPt}$ is approximately twice that of the Ni. ${ }^{[26]}$ This difference in length of the Ni segments can also explain the difference in coercivity of the CoPt segments in the $\mathrm{CoPt} / \mathrm{Ni}$ and $\mathrm{CoPt} / \mathrm{Cu} / \mathrm{Ni} \mathrm{NWs}$. Once the soft Ni segment is reversed, it exerts a dipolar stray field to the CoPt segment (tending to promote its reversal), which adds to the external applied field. Such dipolar stray field is higher for longer Ni segments, thus reducing the coercivity of CoPt.

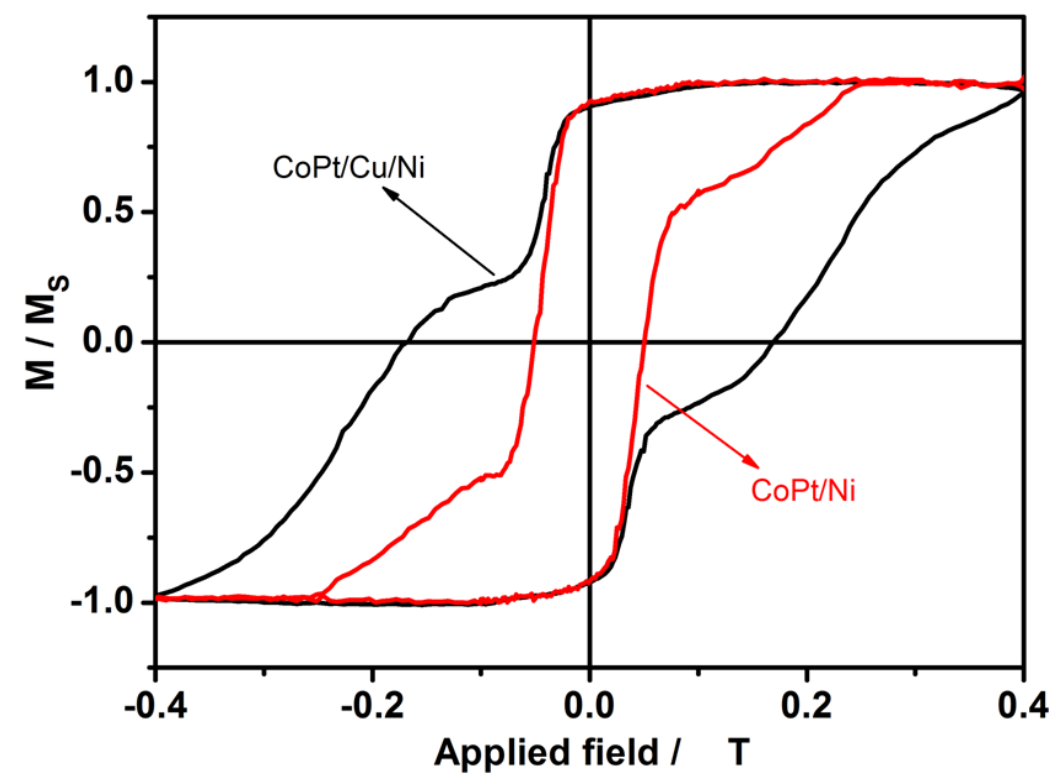

Figure 8. Room-temperature hysteresis loops of tri-segmented $(\mathrm{CoPt}(0.97 \mu \mathrm{m}) / \mathrm{Cu}(2.72$ $\mu \mathrm{m}) / \mathrm{Ni}(1.74 \mu \mathrm{m}))$ and bi-segmented $(\mathrm{CoPt}(0.9 \mu \mathrm{m}) / \mathrm{Ni}(2.9 \mu \mathrm{m})) \mathrm{NW}$ arrays.

\section{Conclusion}

Bi-segmented $\mathrm{CoPt} / \mathrm{Ni} \mathrm{NWs}$ and tri-segmented $\mathrm{CoPt} / \mathrm{Cu} / \mathrm{Ni}$ NWs can be fabricated by electrodeposition in PC membrane by switching between different electrolytes (sequentialelectrodeposition mode). The crystallography of the different segments and the occurrence of texture greatly determine the quality of the resulting interfaces. The $\mathrm{Cu}$ segment cannot accommodate satisfactorily onto CoPt owing to lattice mismatch. As a result, CoPt segment 


\section{WILEY-VCH}

undergoes detachment from the rest of the NW upon PC dissolution. Meanwhile, the structural equivalence existing between (002) hcp CoPt and (111) fcc Ni favors the construction of a good quality junction. Both systems (bi-segmented and tri-segmented NWs) exhibit staircase-like hysteresis loops at room temperature. For the $\mathrm{Cu}$-free $\mathrm{CoPt} / \mathrm{Ni} \mathrm{NWs}$, the occurrence of a staircase-like hysteresis loop indicates that interfacial exchange interactions between the soft and hard counterparts are not sufficient to force a simultaneous magnetization reversal of both segments. The current findings will likely contribute to the advancement in the field of segmented magnetic metallic NWs. In applications requiring the use of isolated NWs or, at least, removal of the template (AAO or PC) (e.g. in NEMS or biomedical applications), the presence of robust interfaces is an essential requirement that needs to be attained before any optimization of the physical, chemical or physicochemical properties of these systems is attempted.

\section{Experimental Section}

Experimental details: Track-etched polycarbonate (PC, Nuclepore, Whatman) membranes with on-top pore diameter ranging from $40 \mathrm{~nm}$ to $60 \mathrm{~nm}$ were used for fabricating the segmented NWs. A thin layer of Au-Pd was sputter deposited onto one side of the PC to serve as working electrode. The PC membrane was sequentially mounted onto a $\mathrm{Cu}$ plate held inside a homemade plastic holder, leaving a circular area of $3.14 \mathrm{~cm}^{2}$ exposed to the electrolyte. The mounted holder was firstly kept in ultrasonic cleaning for 3 min to get rid of the air entrapped inside the pores. All the experiments were performed on a PGSTAT302N Autolab potentiostat/galvanostat (Ecochemie). Platinum spiral was utilized as the counter electrode (CE), which was positioned vertically facing the working electrode (WE). A double junction $\mathrm{Ag} \mid \mathrm{AgCl} 3 \mathrm{M} \mathrm{KCl}$ electrode $(E=+0.210 \mathrm{~V}$ versus standard hydrogen electrode (SCE)) was used as the reference electrode (RE). All chemicals were of analytical grade and 


\section{WILEY-VCH}

used as received without further purification. Electrolyte solutions were prepared from ultrapure water.

$\mathrm{CoPt}, \mathrm{Cu}$ and $\mathrm{Ni}$ segments were prepared by direct current electrodeposition as follows. The CoPt electrolyte consisted of $30 \mathrm{mM} \mathrm{Co}\left(\mathrm{SO}_{3} \mathrm{NH}_{2}\right)_{2} \cdot \mathrm{xH}_{2} \mathrm{O}, 2 \mathrm{mM} \mathrm{Pt}\left(\mathrm{NH}_{3}\right)_{2}\left(\mathrm{NO}_{2}\right)_{2}, 0.1 \mathrm{M}$ glycine, $0.1 \mathrm{M}$ sulfamic acid, $5 \mathrm{mM}$ saccharine and $0.1 \mathrm{M}$ sodium citrate, and the deposition parameters were held constant with $j=-10 \mathrm{~mA} / \mathrm{cm}^{2}, \mathrm{pH}=8.5, \mathrm{~T}=65{ }^{\circ} \mathrm{C} . \mathrm{Cu}$ segment was grown potentiostatically at $E=-1 \mathrm{~V}$ in a bath containing $0.2 \mathrm{M} \mathrm{CuSO}_{4} \cdot 5 \mathrm{H}_{2} \mathrm{O}$ and $0.1 \mathrm{M}$ boric acid. Ni segment was deposited under a constant current density of $-10 \mathrm{~mA} / \mathrm{cm}^{2}$ and the bath contained $0.1 \mathrm{M} \mathrm{NiCl}_{2}$ and $2 \mathrm{M} \mathrm{NH}_{4} \mathrm{Cl}$ as buffer agent. The sequence for segmented NWs deposition was: CoPt segment, $\mathrm{Cu}$ segment and $\mathrm{Ni}$ segment (tri-segmented NWs) or CoPt segment and $\mathrm{Ni}$ segment (bi-segmented NWs). The deposition processes for $\mathrm{Cu}$ and $\mathrm{Ni}$ segments were carried out under $25^{\circ} \mathrm{C}$. Ar was purged through the solution so as to ensure the proper mixture of ions and to remove the gas bubbles from the sample surface. For electron microscopy observations, the segmented NWs were released by dissolving the PC template in chloroform and washed several times afterwards.

Characterization: Scanning electron microscopy (SEM) images and energy-dispersive X-ray spectroscopy (EDX) compositional analyses were acquired using a Merlin Zeiss microscope operated at $3 \mathrm{kV}$ and $15 \mathrm{kV}$, respectively. Specimens were prepared via drop-casting a droplet of NWs suspended in chloroform onto an aluminum foil and subsequent drying in air. Transmission electron microscopy (TEM) analyses were done on a Jeol-JEM 2011 system with a field emission gun operating at $200 \mathrm{kV}$. STEM-EDX analyses were performed on a Tecnai F20 HRTEM / STEM microscope. For both TEM and STEM-EDX observations, a couple of drops of NWs suspended in chloroform were placed onto a carbon-coated TEM grid. X-ray diffraction patterns of the segmented NWs (before PC removal) were recorded on a Philips X'Pert diffractometer in the $30-100^{\circ} 2 \theta$ range $\left(\right.$ step size $=0.026^{\circ}$, step time $\left.=2000 \mathrm{~s}\right)$ 


\section{WILEY-VCH}

using $\mathrm{Cu} \mathrm{K}_{\alpha}$ radiation $(\lambda=0.154178 \mathrm{~nm})$. Hysteresis loops were recorded at room temperature using a vibrating sample magnetometer (VSM) from Oxford Instruments, with a maximum applied magnetic field of 0.5 Tesla.

\section{Supporting Information}

Supporting Information is available from the Wiley Online Library or from the author.

\section{Acknowledgements}

This work has been partially funded by the 2014-SGR-1015 project from the Generalitat de Catalunya, the MAT2014-57960-C3-1-R from the Spanish Ministerio de Economía y Competitividad (MINECO) co-funded by the 'Fondo Europeo de Desarrollo Regional' (FEDER), the MANAQA FET-Open Project from the European Commission (FP7) under the Grant Agreement 296679 and the 2014-Consolidator Grant project n 648454, SPIN-PORICS, from the European Research Council. J.Z. is grateful to the China Scholarship Council (CSC) for the PhD grant. E.P. is grateful to MINECO for the "Ramon y Cajal" contract (RYC-201210839).

Received: ((will be filled in by the editorial staff))

Revised: ((will be filled in by the editorial staff)) Published online: ((will be filled in by the editorial staff))

[1] D. K. Ferry, Science 2008, 319, 579.

[2] W. Zhou, X. Dai, T. M. Fu, C. Xie, J. Liu, C. M. Lieber, Nano Lett. 2014, 14, 1614.

[3] F. Zhang, T. Nyberg, O. Inganäs, Nano Lett. 2012, 2, 1373.

[4] H. Kind, H. Yan, B. Messer, M. Law, P. Yang, Adv. Mater. 2002, 14, 158.

[5] Y. Sun, F. Zhang, L. Xu, Z. Yin, X. Song, J. Mater. Chem. A 2014, 2, 18583.

[6] F. Hernandez-Ramirez, J. D. Prades, A. Tarancon, S. Barth, O. Casals, R. Jimenez-

Diaz, E. Pellicer, J. Rodriguez, J. R. Morante, M. A. Juli, S. Mathur, A. Romano-Rodriguez, Adv. Funct. Mater. 2008, 18, 2990. 


\section{WILEY-VCH}

[7] A. Casadei, E. F. Pecora, J. Trevino, C. Forestiere, D. Rüffer, E. Russo-Averchi, F. Matteini, G. Tutuncuoglu, M. Heiss, A. F. Morral, L. D. Negro, Nano Lett. 2014, 14, 2271.

[8] M. A. Zeeshan, S. Pané, S. K. Youn, E. Pellicer, S. Schuerle, J. Sort, S. Fusco, A. M. Lindo, H. G. Park, B. J. Nelson, Adv. Funct. Mater. 2013, 23, 823.

[9] D. Kagan, R. Laocharoensuk, M. Zimmerman, C. Clawson, S. Balasubramanian, D. Kang, D. Bishop, S. Sattayasamitsathit, L. Zhang, J. Wang, Small 2010, 6, 2741.

[10] K. Liu, K. Nagodawithana, P. C. Searson, C. L. Chien, Phys. Rev. B 1995, 51, 7381.

[11] B. Doudin, G. Redmond, S. E. Gilbert, J. Ph. Ansermet, Phys. Rev. Lett. 1997, 79, 933.

[12] L. Piraux, J. M. George, J. F. Despres, C. Leroy, E. Ferain, R. Legras, K. Ounadjela, A. Fert, Appl. Phys. Lett. 1994, 65, 2484.

[13] B. Özkale, N. Shamsudhin, G. Chatzipirpiridis, M. Hoop, F. Gramm, X. Chen, X. Martí, J. Sort, E. Pellicer, S. Pané, ACS Appl. Mater. Interf. 2015, 7, 7389.

[14] V. Baltz, B. Rodmacq, A. Bollero, J. Ferré, S. Landis, B. Dieny, Appl. Phys. Lett. 2009, 94, 052503.

[15] S. A. Puig. N. D. Valle, E. Pellicer, J. Zhang, J. Nogués, C. Navau, A. Sanchez, J. Sort, New J. Phys. 2016, 18, 013026. [16] J. Sort, B. Rodmacq, S. Auffret, B. Dieny, Appl. Phys. Lett. 2003, 83, 1800.

[17] T. S. Ramulu, R. Venu, B. Sinha, S. S. Yoon, C. G. Kim, Int. J. Electrochem. Sci. 2012, 7, 7762 .

[18] Y. Su, J. Tang, H. Yang, Z. Cheng, Nanoscale 2013, 5, 9709.

[19] D. J. Peña, J. K. N. Mbindyo, A. J. Carado, T. E. Mallouk, C. D. Keating, B. Razavi, T. S. Mayer, J. Phys. Chem. B 2002, 106, 7458.

[20] C. J. Roy, N. Chorine, B. G. De Geest, S. De Smedt, A. M. Jonas, S. D. Champagne, Chem. Mater. 2012, 24, 1562.

[21] Y. K. Su, D. H. Qin, H. L. Zhang, H. Li, H. L. Li, Chem. Phys. Lett. 2004, 388, 406.

[22] A. I. Gapin, X. R. Ye, L. H. Chen, D. Hong, S. Jin, IEEE Trans. Magn. 2007, 43, 2151. 


\section{WILEY-VCH}

[23] K. Y. Kok, C. M. Hangarter, B. Goldsmith, I. K. Ng, N. B. Saidin, N. V. Myung, J. Magn. Magn. Mater. 2010, 322, 3876.

[24] V. M. Pride, J. García, L. Iglesia, V. Vega, D. Görlitz, K. Nielsch, E. D. B. Castro, R. M. Reséndez, A. Ponce, C. Luna, Nanoscale Res. Lett. 2013, 8, 263.

[25] D. S. Xue, H. G. Shi, M. S. Si, J. Phys. : Condens. Matter. 2004, 16, 8775.

[26] J. Zhang, S. A. Puig, N. D. Valle, C. Navau, M. D. Baró, S. Estradé, F. Peiró, S. Pané, B. J. Nelson, A. Sanchez, J. Nogués, E. Pellicer, J. Sort, ACS Appl. Mater. Interfaces 2016, 8, 4109.

[27] J. H. Lee, J. H. Wu, H. L. Liu, J. U. Cho, M. K. Cho, B. H. An, J. H. Min, S. J. Noh, Y. K. Kim, Angew. Chem. Int. Ed. 2007, 46, 3663.

[28] J. U. Cho, Q. X. Liu, J. H. Min, S. P. Ko, Y. K. Kim, J. Magn. Magn. Mater. 2006, $304, \mathrm{e} 213$.

[29] O. Berkh, Y. Shacham-Diamand, E. Gileadi, J. Appl. Electrochem. 2008, 38, 1275.

[30] K. Žužek Rožman, A. Krause, K. Leistner, S. Fähler, L. Schultz, H. Schlörb, J. Magn. Magn. Mater. 2007, 314, 116.

[31] I. Zana, G. Zangari, J. Appl. Phys. 2002, 91, 7320.

[32] P. P. Mardilovich, A. N. Govyadinoy, N. I. Mazurenko, R. Paterson, J. Membrane Sci. 1995, 98, 143.

[33] R. Weil, Annu. Rev. Mater. Sci. 1989, 19, 165.

[34] B. D. Cuillity, Elements of X-ray Diffraction, Addison-Wesley Publishing, Reading, MA, 1978.

[35] J. Duan, J. Liu, D. Mo, H. Yao, K. Maaz, Y. Chen, Y. Sun, M. Ho, X. Qu, L. Zhang, Y. Chen, Nanotechnology 2010, 21, 365605.

[36] J. Amblard, I. Epelboin, M. Froment, G. Maurin, J. Appl. Electrochem. 1979, 9, 233.

[37] C. B. Nielsen, A. Horsewell, M. J. L. Ostergard, J. Appl. Electrochem. 1997, 27, 839.

[38] F. Li, T. Wang, L. Ren, J. Sun, J. Phys. : Condens. Matter. 2004, 16, 8053. 


\section{WILEY-VCH}

[39] A. K. M. Bantu, J. Rivas, G. Zaragoza, M. A. L. Quintela, M. C. Blanco, J. Appl. Phys. 2001, 89, 3393.

[40] K. Ounadjela, R. Ferré, L. Louail, J. M. George, J. L. Maurice, L. Piraux, S. Dubois, J. Appl. Phys. 1997. 81, 5455.

[41] B. Jang, E. Pellicer, M. Guerrero, X. Chen, H. Choi, B. J. Nelson, J. Sort, S. Pané, ACS Appl. Mater. Interfaces 2014, 6, 14583.

[42] W. D. Callister, Jr, Materials Science and Engineering, An Introduction, $5^{\text {th }}$ edition, John Wiley \& Sons, Inc., New York, 2000.

[43] N. D. Nikolic, K. I. Popov, L. J. Pavlovic, M. G. Pavlovic, Surf. Coat. Technol. 2006, $201,560$.

[44] E. Pellicer, A. Varea, S. Pané, B. J. Nelson, E. Menéndez, M. Estrader, S. Suriñach, M. D. Baró, J. Nogués, J. Sort, Adv. Funct. Mater. 2010, 20, 983.

[45] J. E. Davies, O. Hellwig, E. E. Fullerton, J. S. Jiang, S. D. Bader, G. T. Zimányi, K. Liu, Appl. Phys. Lett. 2005, 86, 262503.[46] E. E. Fullerton, J. S. Jiang, S. D. Bader, J. Magn. Magn. Mater. 1999, 200, 392. 


\section{WILEY-VCH}

High quality interfaces in segmented nanowires are crucial for reliable practical applications. The $\mathrm{CoPt} / \mathrm{Ni}$ and $\mathrm{CoPt} / \mathrm{Cu}$ interfaces in electrodeposited $\mathrm{CoPt} / \mathrm{Ni}$ and $\mathrm{CoPt} / \mathrm{Cu} / \mathrm{Ni}$ magnetic nanowires grown by template-assisted electrodeposition are studied in detail. While robust and smooth interfaces develop for $\mathrm{CoPt} / \mathrm{Ni}$, porous and cracked junctions are observed for $\mathrm{CoPt} / \mathrm{Cu}$ due to severe lattice mismatch.

Keywords: segmented nanowires, interfaces, template-assisted electrodeposition, staircaselike hysteresis loop, electrocrystallization

Jin Zhang, Salvador Pané, Jordi Sort*, Eva Pellicer*

Toward robust segmented nanowires: Understanding the impact of crystallographic texture on the quality of segment interfaces in magnetic metallic nanowires

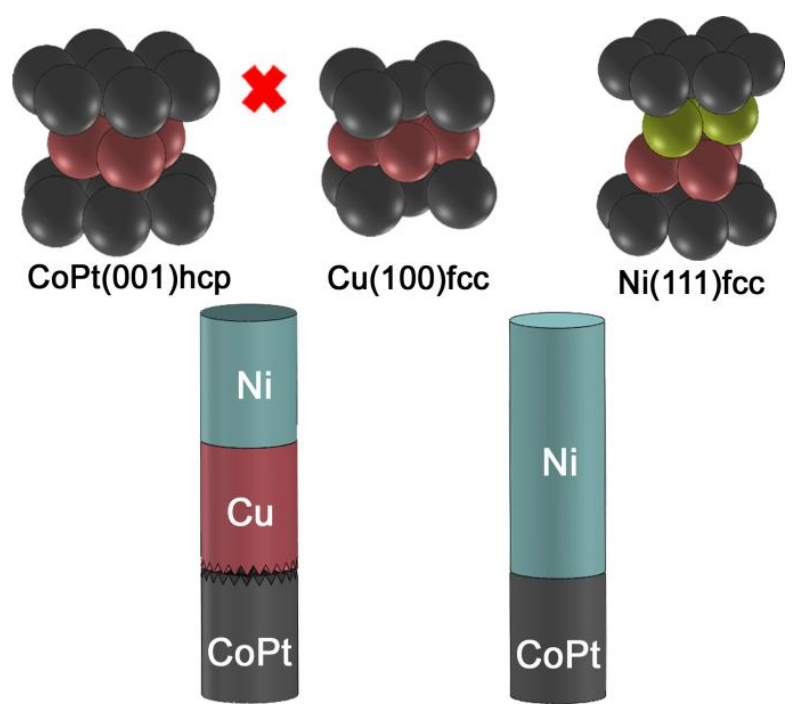




\section{WILEY-VCH}

Copyright WILEY-VCH Verlag GmbH \& Co. KGaA, 69469 Weinheim, Germany, 2013.

\section{Supporting Information}

Toward robust segmented nanowires: Understanding the impact of crystallographic texture on the quality of segment interfaces in magnetic metallic nanowires

Jin Zhang, Salvador Pané, Jordi Sort*, Eva Pellicer*

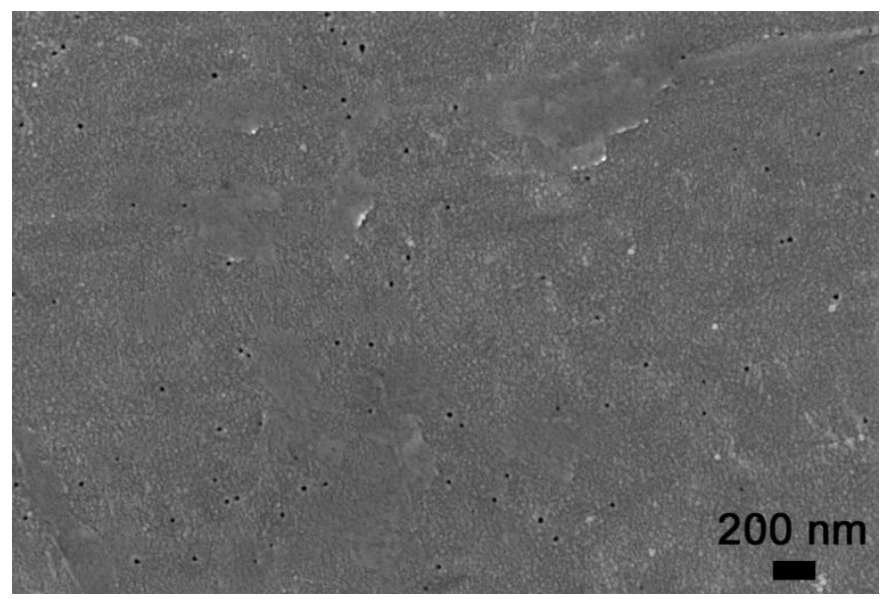

Figure S1. SEM image of polycarbonate (PC) membrane with an on top average pore size of $50 \mathrm{~nm}$ and rather large interpore distance.
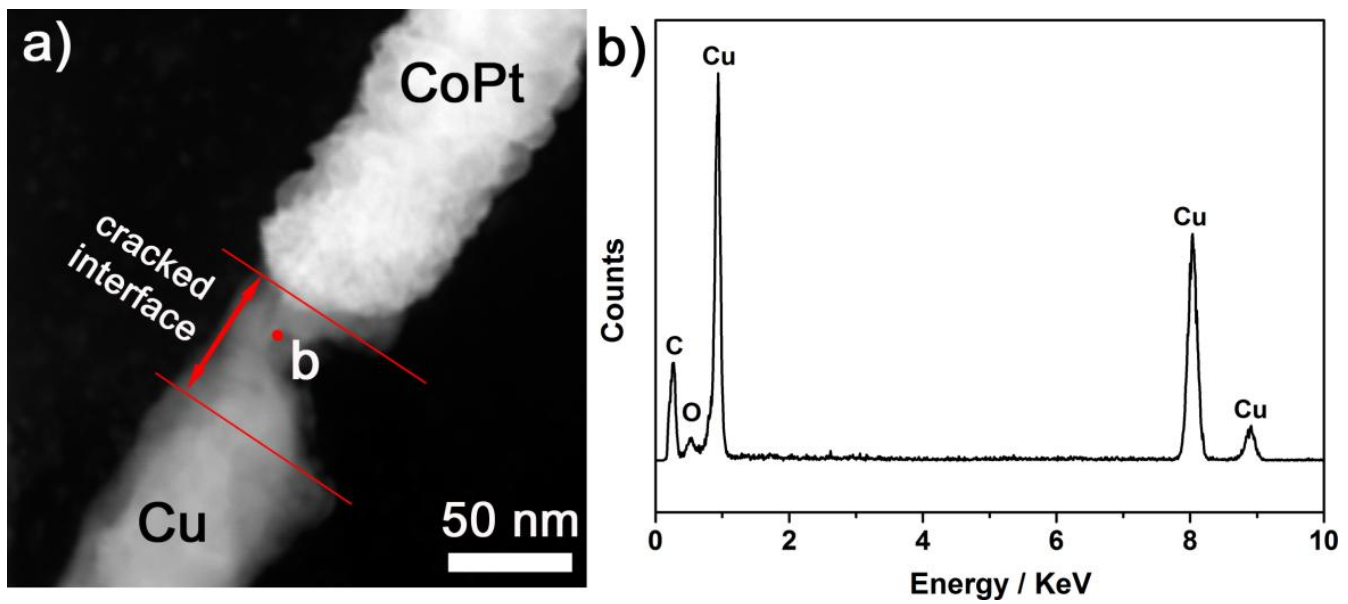

Figure S2. a) TEM image of the cross-sectional view of the CoPt/Cu interface morphology, b) EDX spectrum corresponding to the red dot " $b$ " in a). 


\section{WILEY-VCH}

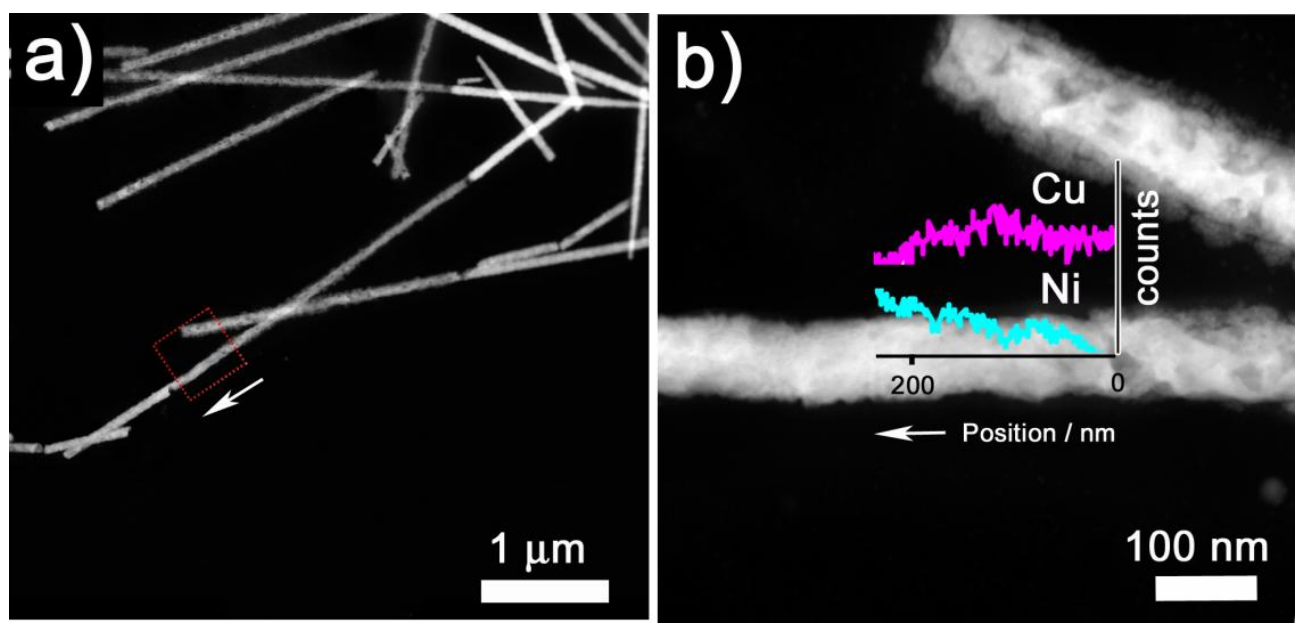

Figure S3. a) TEM image of the tri-segmented CoPt/Cu/Ni NWs. b) STEM-EDX line scan taken at the junction between $\mathrm{Cu}$ and $\mathrm{Ni}$ segments enclosed in the dotted square in a). Images were acquired on a FEI Tecnai $G^{2}$ F20 HR(S)TEM which features enhanced contrast with respect to Jeol-JEM 2011 microscope, thus enabling the location of the $\mathrm{Cu} / \mathrm{Ni}$ junction to some extent. 